ready sale for any or all archaeological material may be found at museums seems rather unfortunate.

Our present policy here at Andover is not to purchase relics indiscriminately. Should any of our friends bring in important specimens that they have purchased in order to preserve them, we are always glad to repay them any expenses that they may have incurred. We do not feel justified in buying any specimen that may turn up without finding out whether it meets our requirements. It must fall in to one of the following classes:

1. Artifacts turned up by accident, such as by agricultural undertakings or construction work.

2. Artifacts acquired by an individual desiring to preserve them from inevitable destruction or loss.

3. Artifacts supported by reliable information as to provenience and manner of occurrence.

We very definitely refuse to purchase artifacts that have been rooted out of the ground with the express intention of selling them, or without regard for the surrounding circumstances. We furthermore reserve the right to refuse to accept gifts of artifacts that are not supported by satisfactory records.

It has been our policy to aid fellow students of archaeology in every possible way, and to share with others the knowledge and information that we have acquired. We will do all in our power to help those who are earnestly interested in perfecting their methods of keeping records, or of securing information, but we will not stir a finger tip for those who are motivated by greed or commercial instincts.

Douglas S. Byers and

FREDERICK JOHNSON

Phillips Academy

Andover, Massachusetts

\title{
Lithic Problems
}

In every science the matter of nomenclature is a basic stumbling block which must be surmounted in order that ideas and accomplishments of any may be interpreted and correlated by all.

In the Lithic Laboratory for the Eastern United States, we have found it necessary to take certain steps toward uniformity in order that we may effectually achieve our ultimate aim of correlation between the primitive implements which are discovered and the occurrence of the outcrops from which the material was procured by the aborigines.

Since numerous errors in the identification of lithic materials have been made in archaeological papers in the past, as most will admit, the work of these writers is nugatory as far as the Lithic Laboratory is concerned unless these particular specimens are available for our own identification.

A fairly accurate study of the works of thirty-five of the foremost geolo- 
gists, petrologists, and mineralogists discloses a definite splitting into at least six groups over the question of a distinction between flint and chert. Hence, one scarcely wonders at the inability of the archaeologists to make mineral identifications.

However, in an attempt to bring some semblance of uniformity into the nomenclature where it will apply in studies of the Lithic Laboratory, and since it is apparent that the aforementioned geologists, petrologists, and mineralogists have not reached a satisfactory agreement, we will refer to James Dwight Dana as our authority in making definite and specific identifications; but for a general term to include such widely used and closely allied siliceous materials as chert, hornstone, basanite, pthanite, touchstone, Lydianite, silex, novaculite, jasper, et cetera, "flint" will be employed, since we feel that it is a term more generally known and with a more distinct meaning for the average person than any other of the more or less synonymous terms expressed above.

We sincerely appreciate the whole-hearted cooperation which has been accorded the Lithic Laboratory since its inception and would welcome any suggestions on this matter of nomenclature or other subjects pertinent to our work.

H. Holmes Ellis

Research Associate

Lithic Laboratory

March 11938 